\title{
UCRL-TR-206891
}

LAW RENCE LIVERMORE N A TIO N A L LABORATORY

\section{Micro-Compatibility Testing of Polysulfone}

H. Gregg, C. Harvey, R. Maxwell, A. Vance

September 30, 2004 
This document was prepared as an account of work sponsored by an agency of the United States Government. Neither the United States Government nor the University of California nor any of their employees, makes any warranty, express or implied, or assumes any legal liability or responsibility for the accuracy, completeness, or usefulness of any information, apparatus, product, or process disclosed, or represents that its use would not infringe privately owned rights. Reference herein to any specific commercial product, process, or service by trade name, trademark, manufacturer, or otherwise, does not necessarily constitute or imply its endorsement, recommendation, or favoring by the United States Government or the University of California. The views and opinions of authors expressed herein do not necessarily state or reflect those of the United States Government or the University of California, and shall not be used for advertising or product endorsement purposes.

This work was performed under the auspices of the U.S. Department of Energy by University of California, Lawrence Livermore National Laboratory under Contract W-7405-Eng-48. 


\title{
Micro-Compatibility Testing of Polysulfone
}

\author{
Hugh Gregg, Chris Harvey, Robert Maxwell \& Andrew Vance \\ Weapon Materials Compatibility \& Aging \\ Chemistry and Chemical Engineering Division \\ Lawrence Livermore National Laboratory
}

\section{Introduction}

Polysulfone has many useful properties, and its compatibility with other materials is of interest. It is a tough, rigid, high-strength thermoplastic that maintains its properties over a wide temperature range. It is chemically resistant to mineral acids and alkali and moderately resistant to hydrocarbon oils; however, it is not resistant to polar organic solvents such as ketones, chlorinated hydrocarbons and aromatic hydrocarbons. Micro-compatibility experiments were initiated to determine possible detrimental interactions in a sealed environment between polysulfone components and a number of other organic species.

\section{Experimental}

Small quantities (5-50 mg; typically 5-10 mg) of several materials (Table 1) were placed in sealed headspace vials. For each test matrix, each component was tested individually, in pairs with every other compound, in triples, quads, and for test matrix \#1, sets of 5 and all six compounds. Four vials were prepared of each combination, along with a blank (Figure 1). The blank and the two control samples were left at room temperature, and the remaining two samples were heated in an oven at $70^{\circ} \mathrm{C}$ for two weeks.

Table 1: Two test matrices used in this study.

\begin{tabular}{cc}
\hline Test matrix \#1 & Test matrix \#2 \\
\hline Polysulfone & Polysulfone \\
TATB & PBX9502 (TATB \& Kel-F) \\
Kel-F & \\
OXY461 & PBX9407 (RDX \& OXY461) \\
RDX & XTX8004 (RDX \& Sylgard) \\
Sylgard & \\
\hline
\end{tabular}

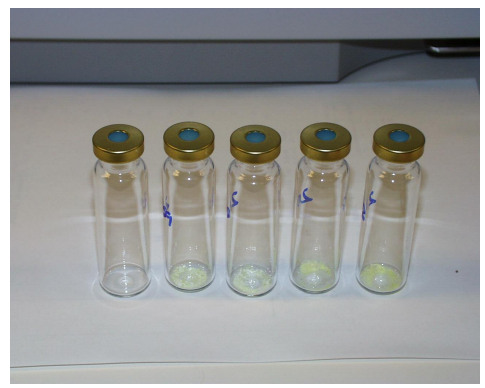

Figure 1. Headspace vials with test materials. 
The samples were analyzed by solid phase microextraction gas chromatography mass spectrometry (SPME GC/MS) using an automated system (Figure 2). The analysis conditions were as follows: $75 \mu \mathrm{m}$ Carboxen-PDMS SPME fiber, conditioned for 20 minutes at $260^{\circ} \mathrm{C}$; headspace sampled at $50^{\circ} \mathrm{C}$ for 60 seconds, and "injected" into the $\mathrm{GC}$ for 30 seconds at $250^{\circ} \mathrm{C}$. The Agilent $6890 \mathrm{GC}$ was set for splitless injection, purge @0.5 min., using a Restek RTX5-MS column $(30 \mathrm{~m}, 0.25 \mathrm{~mm}$ ID, $0.25 \mu \mathrm{m}$ film) with a $1.0 \mathrm{~mL} / \mathrm{min}$ constant flow of helium. The 20 minute run had the following temperature profile: $40^{\circ} \mathrm{C} / 2 \mathrm{~min}, 15^{\circ} \mathrm{C} / \mathrm{min}$ to $300^{\circ} \mathrm{C}$, hold 0.67 min. An Agilent 5973 mass spectrometer scanned the mass range from 20-450 at a rate of 1.75 scans/sec with a filament delay of $2.75 \mathrm{~min}$.

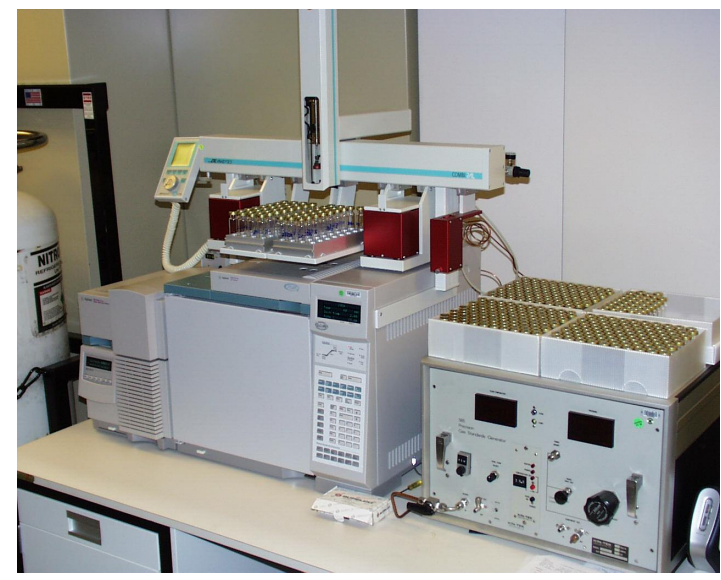

Figure 2: The automated SPME headspace analysis GC/MS system.

\section{Results}

The multiple sample matrices utilized for this study generated large amounts of data, but many of the matrices did not provide new information and can be disregarded. The most valuable results were obtained from the series of binary matrices (two materials), and that data will be the focus of this report. In general, most of the polysulfone interactions were benign with only simple combinations of the chromatograms of the two matrix components, indicative of no interaction between the components. These results are summarized in Table 2. There were two cases where changes in the chromatograms were observed, and these are discussed in more detail below.

Table 2. Summary of results of polysulfone binary matrices.

\begin{tabular}{lcc}
\hline Component 1 & Component 2 & Result \\
\hline Polysulfone & TATB & No interaction \\
Polysulfone & Kel-F & Additional Kel-F fragments vs Kel-F alone \\
Polysulfone & OXY461 & Additional OXY fragments vs OXY461 alone \\
Polysulfone & RDX & No interaction \\
Polysulfone & Sylgard & No interaction \\
Polysulfone & PBX9502 & No interaction \\
Polysulfone & PBX9407 & No interaction \\
Polysulfone & XTX8004 & No interaction \\
\hline
\end{tabular}


Polysulfone/TATB. Polysulfone showed no compatibility issues with TATB in these tests, and the analysis of this matrix serves as an example of non-interactive components. As shown in Figure 4, the chromatogram of polysulfone alone includes only peaks corresponding to the SPME fiber and trace amounts of chlorobenzene. (Trichloroethylene, an organic solvent, has also been observed in larger polysulfone samples.) TATB alone shows only the same SPME fiber peaks and some toluene. The GC trace of the polysulfone/TATB matrix shows only a combination of the two individual chromatograms, indicating no destructive interactions are occurring between the two components.
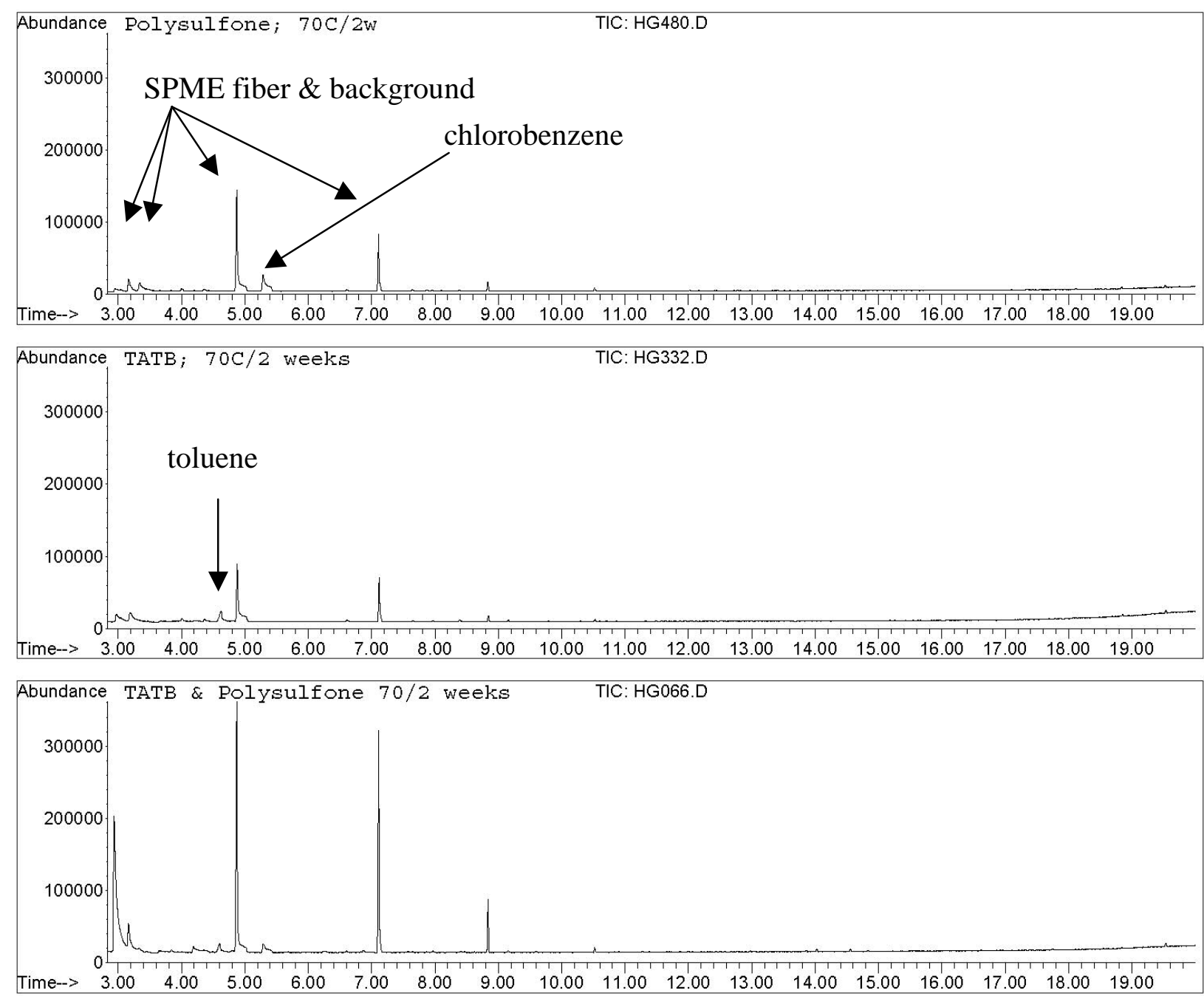

Figure 3. Top: Polysulfone alone. Middle: TATB alone. Bottom: TATB + polysulfone.

Polysulfone/Kel-F. The polysulfone/Kel-F matrix showed additional Kel-F fragments in the chromatogram, indicating Kel-F degradation; however, in the matrix with PBX9502, which incorporates $5 \%$ Kel-F binder, no significant Kel-F fragments were observed. The results are shown in Figure 4. The exact cause of the apparent Kel-F degradation has not yet been determined, but it may be the result of a reaction between the fluoropolymer Kel-F and trichloroethylene and/or chlorobenzene that are present in the polysulfone. 
Polysulfone/OXY461. Polysulfone also seems to contribute to the breakdown of OXY461, as additional OXY461 fragments were observed in the chromatogram of that matrix. In contrast, in the matrix with PBX9407, which includes OXY461 as a component, no significant OXY461 fragments were observed.
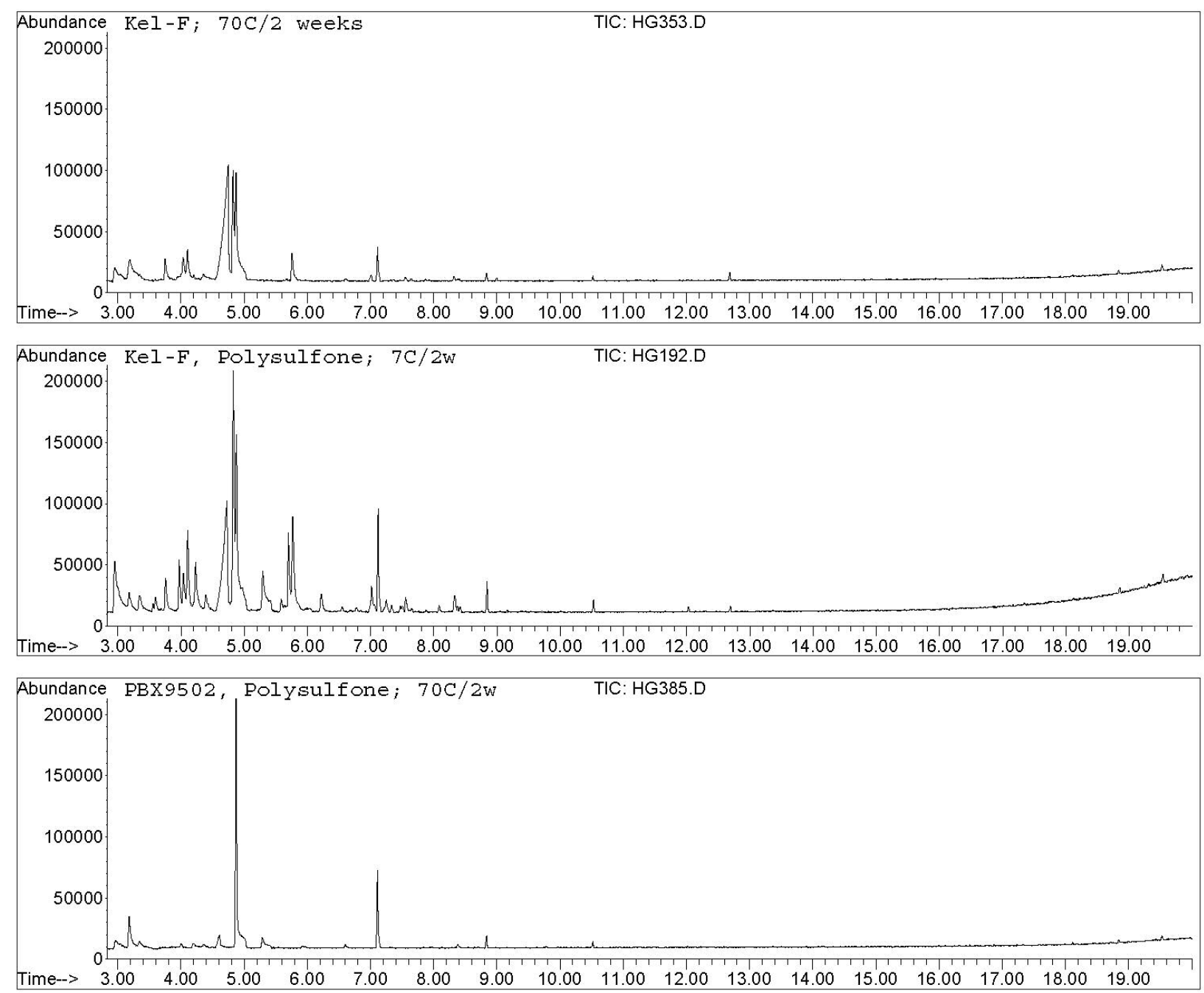

Figure 4. Top: Kel-F alone. Middle: Kel-F + Polysulfone. Bottom: PBX9502 + Polysulfone.

\section{Conclusions}

Micro-compatibility experiments have been completed for the interaction of polysulfone with a series of materials of interest. While further data analysis is needed to completely define the interactions observed in the sample matrices, some general conclusions can be drawn. In most cases, polysulfone does not appear to interact with the other organic species that were tested. While polysulfone is known to be sensitive to organic solvents, preliminary results with the current analytical technique do not show degradation products of polysulfone. In only two cases did polysulfone display an interaction with other materials. Kel-F and OXY461 degradation appeared to be promoted by the presence of polysulfone, although fragments of those materials were not observed in the matrices including PBX9502 and PBX9407. 
Polysulfone, with its ether (C-O-C) and sulfone linkages (Figure 5), might be expected to yield polar (partially charged) degradation products such as sulfonates or phenol derivatives. The

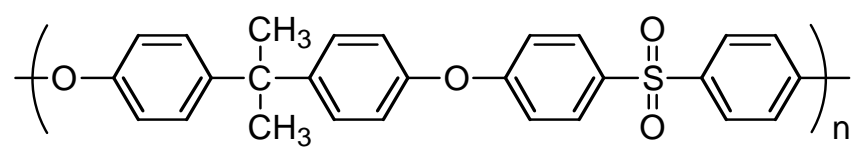

Figure 5. Structure of polysulfone.

SPME fiber and GC column utilized in these experiments were optimized for nonpolar (noncharged) compounds so some potential polysulfone degradation products might not be observed without changing the analytical setup. Additional experiments with the binary polysulfone matrices could be carried out with a SPME fiber and GC column designed to collect and separate polar compounds. These are readily available commercially and could be incorporated into existing instrumentation.

Finally, SPME GC/MS experiments on a sealed system FSET showed a significant level of toluene (Figure 6). The presence of toluene in an enclosed system could lead to polysulfone degradation, and polysulfone/toluene interactions should be examined.

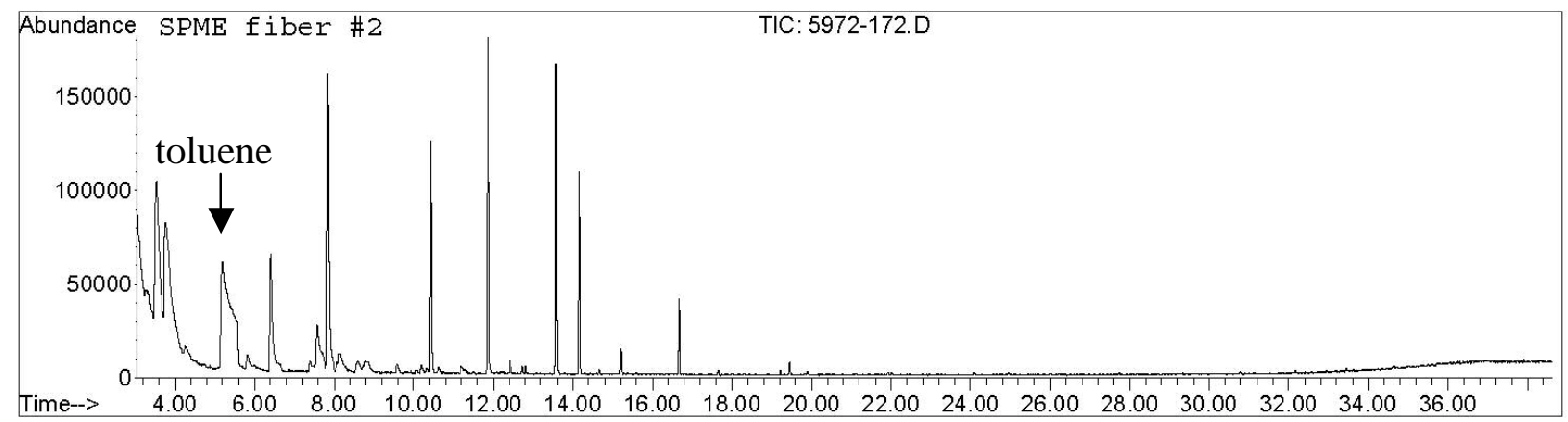

Figure 6. FSET SPME GC/MS. 